\title{
The Effect of Subcutaneous Epinephrine Dosage on Blood Loss in Surgical Incisions
}

\author{
Seyed Esmail Hassanpour ${ }^{1}$, Hatef Zirakzadeh ${ }^{1 *}$, Yasaman Aghajani²
}

1. Department of Plastic and Reconstructive Surgery, Shahid Beheshti University of Medical Sciences, Tehran, Iran;

2. Department of Anesthesiology; Khatam Al Anbia hospital, Tehran, Iran

*Corresponding Author:

Hatef Zirakzadeh, MD;

Resident of Department of Plastic and

Reconstructive Surgery,

Shahid Beheshti University of Medical

Sciences,

Tehran, Iran.

Email: Htfzrk@yahoo.com

Received: February 6, 2020

Revised: July 19, 2020

Accepted: July 27, 2020

\section{ABSTRACT}

\section{BACKGROUND}

Epinephrine is commonly used in plastic and reconstructive surgeries to reduce the blood loss, and to achieveing the lowest and the most effective dosage of epinephrine can improve the results of the surgery.

\section{METHODS}

Thirty two rats were divided in four groups. Local injection of epinephrine solution $(3 \mathrm{~mL})$ with concentrations of 1:200,000, $1: 400,000$ and 1:1,000,000 was undertaken in three different groups; and the fourth group was the control in which $3 \mathrm{~mL}$ of normal saline was administered 15 minutes before making the incision. The bleeding amount was compared in these groups.

\section{RESULTS}

A significant difference in blood loss was noted between the control and other groups, but no significant difference was present between epinephrine concentrations of 1:200,000, 1:400,000 and $1: 1,000,000$.

\section{CONCLUSION}

Local injection of epinephrine solution was shown to reduce bleeding from surgical incisions, but the difference between various pinephrine concentrations was not significant. The use of the lowest concentration $(1: 1,000,000)$ was suggested to decrease epinephrine side effects.

\section{KEYWORDS}

Epinephrine; Incision; Bleeding; Rat

Please cite this paper as:

Hassanpour SE, Zirakzadeh H, Aghajani Y. The Effect of Subcutaneous Epinephrine Dosage on Blood Loss in Surgical Incisions. World J Plast Surg 2020;9(3):309-312. doi: 10.29252/wips.9.3.309.

\section{INTRODUCTION}

Surgical incision and skin damage is inevitable in surgeries, while bleeding due to these incisions happens. Bleeding is one of the most important complications in plastic surgery and injection of epinephrine has been widely used to decrease the amount of blood loss. Bleeding during surgery may cause complications, like hemoglobin decrease which may lead to blood transfusion..$^{1-3}$ Bleeding has also adverse effects on wound healing process and aesthetic results and may cause cardiovascular and systemic side effects too. Wound bleeding can lead to more complications, especially in aesthetic and reconstructive surgeries, since these 
operations have longer surgical times and bleeding in surgical field may interfere with delicate surgery and anatomical plans on view. ${ }^{4,5}$

Some different methods have been used to decrease the bleeding amount during the operation such as controlled hypotensive state surgery and infiltration of vasoconstrictive drugs. All of these methods have their side effects and complications. Nowadays, vasoconstrictive drugs and especially subcutaneous epinephrine are commonly used in aesthetic and reconstructive surgeries to control bleeding., Epinephrine has been used in different doses for this purpose. It has local and systemic side effects and some of these side effects are severe cardiovascular complications, such as tachycardia, hypertension and even sometimes cardiac arrest and death. Epinephrine is used in concentrations from $1: 100,000$ to $1: 1,000,000$ and there is no consensus over standard dose of this vasoconstrictor for optimal results. ${ }^{2,4,7}$ Epinephrine side effects are dose dependent, and by decreasing epinephrine dosage, the side effects can decrease. In this study we assessed the effect of different doses of epinephrine on bleeding amount of surgical wounds in experimental rat model to suggest the optimal dosage of epinephrine to balance its effect on bleeding.

\section{MATERIALS AND METHODS}

This study is a randomized prospective study

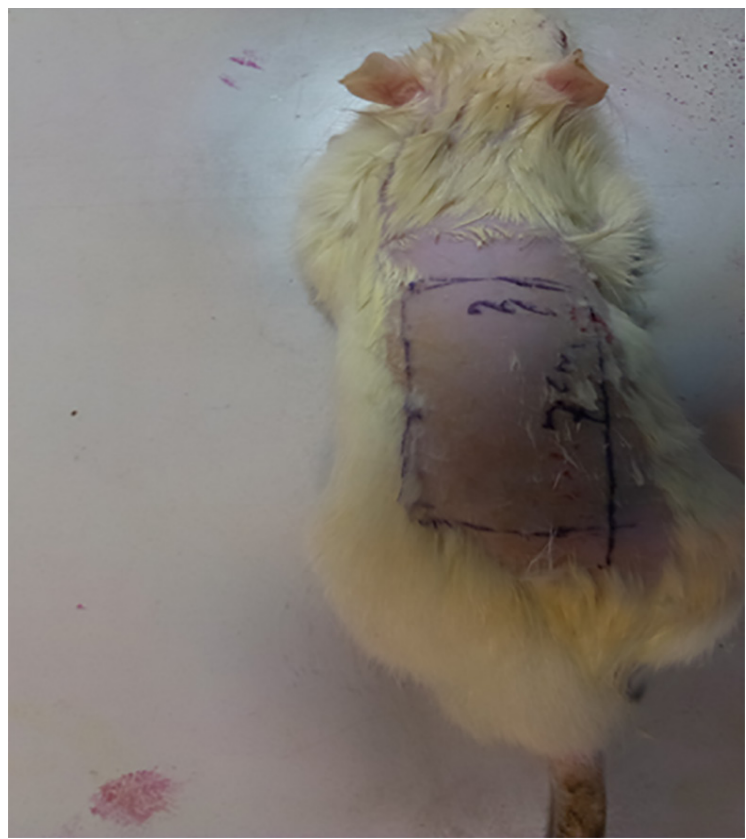

Fig. 1: Designing the flap. approach. Guidelines of the Declaration of Helsinki were followed in this research and the study was approved in the institution ethics committee. Thirty two healthy rats weighing 250 to $320 \mathrm{~g}$ (Mean: $300 \mathrm{~g}$ ) were divided into four groups of 8 animals. Rats were anesthetized with $100 \mathrm{mg} / \mathrm{kg}$ of ketamine and $50 \mathrm{mg} / \mathrm{kg}$ of xylazine. The lumbar region of rats was shaved and a random pattern flap with $3 \times 7 \mathrm{~cm}$ dimension was designed in this region (Figure 1).

Three milliliters of epinephrine in normal saline with different concentrations of 1:200,000, $1: 400,000$ and 1:1,000,000 were injected subcutaneously under the designed flaps, before making the incision in three different groups of rats, while each group was consisted of eight rats. In the control group, only $3 \mathrm{~mL}$ of normal saline was used. Incisions were made 15 minutes after the injection and flaps were released (Figure 2). Bleeding was measured for 5 minutes by using $1 \times 1$ inch gauze. We weighed the gauze before making the incision and then weighed the gauze again after 5 minutes, when it was soaked with blood. We measured the weight of one milliliter of blood of rats and it was $0.95 \mathrm{~g}$ and we used this ratio to measure the blood loss. Analysis of data was done with SPSS software (version 16, Chicago, IL, USA). A p value less than 0.05 was considered statistically significant.

\section{RESULTS}

The average amount of bleeding in 1:200,000,

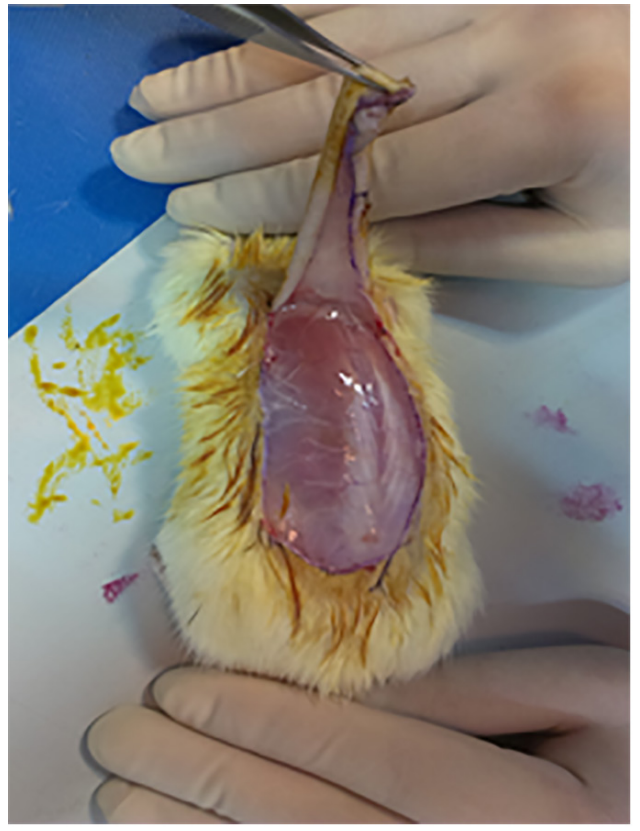

Fig. 2: Elevating the flap. 
$1: 400,000,1: 1,000,000$ groups were 0.2525 $\mathrm{mL}, 0.2775 \mathrm{~mL}$ and $0.2638 \mathrm{~mL}$, respectively and the difference between these groups was not significant $(p>0.5)$. The average amount of bleeding in the control group was 0.5038 $\mathrm{mL}$ and had a significant difference with other groups $(p<0.001)$.

\section{DISCUSSION}

This study illustrated that different concentration of epinephrine decreased the amount of bleeding from surgical incisions. Neither the lowest nor the highest epinephrine concentration could reduce bleeding amount from surgical field. All epinephrine concentrations resulted in same side effects. ${ }^{8-10}$ Different approaches have been tried to enhance vasoconstrictor effects, at the same time to reduce the dosage. Thus the optimum concentration of epinephrine for the prevention of bleeding has not been clearly resolute, ${ }^{11}$ we suggested to administer lower concentrations of epinephrine to decline the side effects, and perhaps 1:1,000,000 concentration has been the best dosage with the least complications. Epinephrine may also have an adverse effect on flap survival due to its vasoconstrictive effect and this will need further study. ${ }^{11}$

Another method to reduce epinephrine and local anesthetic concentration is to use them as combination this may also prolongs analgesia. To lessen the dosage of epinephrine, the lowest preferred dose should be administered to achieve vasoconstriction. ${ }^{12} \mathrm{Kim}$ et al. suggested that epinephrine concentrations between 1:100,000 and 1:400,000 were similarly effective and provided better vasoconstriction when compared with more diluted solutions. If epinephrine is more diluted, its characteristics such as onset and time to peak serum concentrations may be influenced and also the duration of action is shortened..$^{13}$

We have to consider that the optimum safe dose of local anesthetics is more dependent on the route, rate and the site of injection than the drug load. ${ }^{13}$ As mentioned before, site and sort of surgery affect optimum concentrations of epinephrine; while in dermatologic plastic surgeries, epinephrine in 1:50,000 concentration is used to reduce the amount of bleeding with satisfying results. ${ }^{14}$ The prevalence of cardiovascular toxic adverse effects has been observed to increase in a dose dependent manner. ${ }^{15,16}$ Many authors applied 1:200,000 concentration of epinephrine to control bleeding in aesthetics surgery, but we suggested administration of lower doses as described before. ${ }^{6}$ Yang and colleagues showed that before scalp incision in craniotomy, different concentrations of epinephrine have no significant effect on bleeding and this is compatible with our findings too. ${ }^{6}$

\section{CONCLUSION}

We found that epinephrine can decrease bleeding from surgical incisions, but there was no different between 1:200,000, 1:400,000 and $1: 1,000,000$ concentrations. So we suggested choosing lower concentrations.

\section{ACKNOWLEDGMENT}

We would like to appreciate the kind support of Shahid Beheshti University of Medical Sciences.

\section{CONFLICT OF INTEREST}

The authors declare no conflict of interest.

\section{REFERENCES}

1 Fujita K, Mishima Y, Iwasawa M, Matsuo $\mathrm{K}$. The practical procedure of tumescent technique in burn surgery for excision of burn eschar. J Burn Care Res 2008;29:924-6. doi: 10.1097/BCR.0b013e31818b9e7a.

2 Yang JJ, Wang QP, Wang TY, Sun J, Wang ZY, Zuo D, Xu JG. Marked hypotension induced by adrenaline contained in local anesthetic. Laryngoscope 2005;115:348-52. doi: 10.1097/01.mlg.0000154752.94055.72.

3 Furia JP,Zambetti GJ, Jr. An injection technique to create a bloodless field in arthroscopically assisted anterior cruciate ligament reconstruction. Am J Sports Med 1992;20:4069. doi: 10.1177/036354659202000407.

4 Maguiña P, Velez M. Review of epinephrine solution use in 400 consecutive cases of burn reconstruction. Are infusion pumps safe? Journal of Burn Care \& Research 2013;34:e305-e7. doi: 10.1097/ BCR.0b013e3182779a4a.

5 Rodrigues FV, Hochman B, Wood VT, Simoes MJ, Juliano Y, Ferreira LM. Effects of lidocaine with epinephrine or with buffer 
on wound healing in rat skin. Wound Repair Regen 2011;19:223-8. doi: 10.1111/j.1524475X.2010.00654.x.

6 Liu J-CS, Zhou Z-q. Epinephrine Infiltration on Nasal Field Causes Significant Hemodynamic Changes: Hypotension Episode Monitored by Impedance-cardio-graphy under General Anesthesia. J Pharm Pharmaceut Sci 2006;9:190-7.

7 Liu S, Carpenter RL, Chiu AA, McGill TJ, Mantell SA. Epinephrine Prolongs Duration of Subcutaneous Infiltration of Local Anesthesia in a Dose-related Manner:: Correlation With Magnitude of Vasoconstriction. Regional Anesthesia: The Journal of Neural Blockade in Obstetrics, Surgery, \& Pain Control 1995;20:378-84.

8 Folwaczny C, Heldwein W, Obermaier G, Schindlbeck N. Influence of prophylactic local administration of epinephrine on bleeding complications after polypectomy. Endoscopy 1997;29:31-3. doi: 10.1055/s-2007-1004058.

9 Guinard J-P, Carpenter RL, Morell RC. Effect of local anesthetic concentration on capillary blood flow in human skin. Regional Anesthesia: The Journal of Neural Blockade in Obstetrics, Surgery, \& Pain Control 1992;17:317-21.

10 Chow YC, Yang S, Huang CJ, Tzen CY, Huang PL, Su YH, Wang PS. Epinephrine promotes hemostasis in rats with cyclophosphamide-induced hemorrhagic cystitis. Urology 2006;67:636-41. doi: 10.1016/j.urology.2005.10.003.
11 Dunlevy TM, O’Malley TP, Postma GN. Optimal concentration of epinephrine for vasoconstriction in neck surgery. Laryngoscope 1996;106:1412-4. doi: 10.1097/00005537-199611000-00020.

12 O'Malley TP, Postma GN, Holtel M, Girod DA. Effect of local epinephrine on cutaneous bloodflow in the human neck. Laryngoscope 1995;105:140-3. doi: 10.1288/00005537199502000-00005.

13 Kim H, Hwang K, Yun SM, Kim DJ. Usage of Epinephrine Mixed With Lidocaine in Plastic Surgery. J Craniofac Surg 2020;31:791-3. doi: 10.1097/SCS.0000000000006156.

14 Shoroghi M, Sandrolsadat SH, Razzaghi M, Farahbakhsh F, Sheikhvatan M, SheikhfathollahiM, Abbasi A. Effect of different epinephrine concentrations on local bleeding and hemodynamics during dermatologic surgery. Acta dermatovenerologica Croatica 2008;16:209-214.

15 HORRIGAN RW, EGER EI, WILSON C. Epinephrine-induced arrhythmias during enflurane anesthesia in man: a nonlinear dose-response relationship and dosedependent protection from lidocaine. Anesthesia \& Analgesia 1978;57:547-50. doi: 10.1213/00000539-197857050-00007.

16 Murthy HS, Rao GU. Cardiovascular responses to scalp infiltration with different concentrations of epinephrine with or without lidocaine during craniotomy. Anesthesia \& Analgesia 2001;92:1516-9. doi: 10.1097/00000539-200106000-00032. 